Article

\title{
Exploring Challenges and Opportunities of Biophilic Urban Design: Evidence from Research and Experimentation
}

\author{
Maria Beatrice Andreucci ${ }^{1, *(1)}$, Angela Loder ${ }^{2}$, Martin Brown ${ }^{3}$ and Jelena Brajković ${ }^{4}$ \\ 1 Department of Planning, Design, Technology of Architecture, Sapienza University of Rome, 00196 Rome, Italy \\ 2 International WELL Building Institute, New York, NY 10001, USA; angela.loder@wellcertified.com \\ 3 Fairsnape, Inglewhite, Lancashire PR3 2LE, UK; fairsnape@gmail.com \\ 4 Faculty of Architecture, University of Belgrade, 11120 Belgrade, Serbia; jelena.brajkovic@arh.bg.ac.rs \\ * Correspondence: mbeatrice.andreucci@uniroma1.it
}

check for

updates

Citation: Andreucci, M.B.; Loder, A.; Brown, M.; Brajković, J. Exploring Challenges and Opportunities of Biophilic Urban Design: Evidence from Research and Experimentation. Sustainability 2021, 13, 4323. https:// doi.org/10.3390/su13084323

Academic Editors: Israa

H. Mahmoud, Eugenio Morello, Giuseppe Salvia and Emma Puerari

Received: 27 February 2021

Accepted: 10 April 2021

Published: 13 April 2021

Publisher's Note: MDPI stays neutral with regard to jurisdictional claims in published maps and institutional affiliations.

Copyright: (C) 2021 by the authors Licensee MDPI, Basel, Switzerland. This article is an open access article distributed under the terms and conditions of the Creative Commons Attribution (CC BY) license (https:/ / creativecommons.org/licenses/by/ $4.0 /)$.

\begin{abstract}
Global health emergencies such as Covid-19 have highlighted the importance of access to nature and open spaces in our cities for social, physical, and mental health. However, there continues to be a disconnect between our need for nature and our daily lived experience. Recent research indicates that our connectedness and relationship with nature, and in particular biophilic design, may be key for improving both health and quality of life. Rather than relying on abstract universal ideas of "nature", using evidence-based biophilic design and policy at a building, neighborhood, and city scale, to link our daily lives with biodiversity, may encourage sense of place and make environmental action more meaningful. Then, improving our natural capital in the urban built environment might help address the current climate and disease crisis, as well as improving our physical and mental health. Drawing from emerging research and innovative practice, the paper describes key research and design paradigms that influence the way we understand the benefits of nature for different environments, including the workplace, neighborhood, and city, and explains where biophilic design theory sits in this field. Examples from recent research carried out in London and Chicago are provided, aiming at demonstrating what kind of research can be functional to what context, followed by a detailed analysis of its application supporting both human and ecological health. The study concludes indicating key policy and design lessons learned around regenerative design and biophilia as well as new directions for action, particularly with regard to climate change, sense of place, and well-being.
\end{abstract}

Keywords: biophilia; greening cities; health and well-being; nature-based solutions; urban design; urban green infrastructure

\section{Introduction}

Improved environmental and human health outcomes have long been associated with the integration of nature into our urban form [1-3]. Pandemics such as Covid-19 have highlighted again the importance of access to nature and open spaces in our cities for our social, physical, and mental health [4]. People living in neighborhoods with worse air pollution-which also often lacks greenspace-have been shown to have a higher death rate from Covid-19 [5]. Access to urban nature has also been shown to be influential in stress reduction and socialization [6,7], with urban parks receiving attention on the benefits of nature as urbanites seek out safer outdoor space in which to work, socialize, and play [8]. This renewed attention is supported by a trend in urban planning and design that is trying to provide opportunities to connect urbanites with nature through communitybased ecosystem services projects, regenerative and biophilic design interventions, and residential greenspace, all of which have been linked to increased well-being, concentration, socialization, sense of place, and a connection with nature [9].

However, there continues to be a disconnect between our need for nature, our daily lived experience, and sustainable behavior. This is a missed opportunity given that a 
recent systematic research [6,7] has suggested that our connectedness and relationship with nature, and in particular our experience of biophilic design, may be key for improving both sustainability and our quality of life. However, though there is over forty years of research on the benefit of access to nature for human and climate health, there is still confusion in the sustainability and design fields on exactly what types of nature can lead to which types of benefit, and for whom. This confusion is partly rooted in a failure to understand how to interpret and apply research on nature and health to different design and policy interventions at different scales [10]. Specifically, issues arise from a disconnection between biophilic design principles, urban planning interventions, and specific health and well-being outcomes, as well as from a lack of integration between different disciplines. This confusion has real implications as buildings, cities, and regions attempt to align regenerative design goals with human health ones but often lack the tools and knowledge to do so, which can result in a lack of evidence to support the effectiveness of these interventions.

The identification of these issues has led to the research objectives of this paper. Specifically, this paper aims to (a) give researchers, designers, and urban planners a better understanding of the types of research on the benefits of nature, particularly studies following an adaptive or utilitarian paradigm, (b) compare this research to the most wellknown application of these principles, i.e., biophilic design; (c) evaluate how real-world case studies in London and Chicago have used (or not used) this research and design foundation for positive human and ecological outcomes, and (d) provide detailed analysis of where biophilic design is working well and highlight new directions and opportunities that can help to address current shortfalls. Drawing from established and emerging theories and innovative practice, this contribution evaluates key research and design paradigms that influence the way we understand the benefits of nature, and then uses this foundation to assess the effectiveness of three applied case studies according to different pathways, and at different scales: the workplace, the neighborhood, and the city. The paper finally reflects on key policy and design lessons learned about regenerative design and biophilia and how these can be leveraged for a better connection with nature and a sense of place, which may make environmental action more meaningful. The study is structured as follows: Section 2 explains the methodology; Section 3 presents the conceptual framework, in which the theoretical and practical interrelations between regenerative design and biophilia are highlighted; Section 4 introduces and develops the London and Chicago case studies; Section 5 elaborates results and their discussion; and Section 6 presents the conclusions.

\section{Methods}

In order to achieve the objectives mentioned, the work has adopted a mixed-qualitative methodology that has been structured developing a combination of critical literature review and field research. A critical, in-depth review of the theoretical paradigms, underlying the most influential scientific programs on nature and health, was undertaken with the goal to understand how the paradigms influenced the kind of study that comes out of these research programs, the goals of this investigation, as well as how and why this research has been influential in policy circles, highlighting limitations and new directions. A more extensive analysis, from which this review is based, can be found in [11], as well as in [6,7], two systematic reviews (Cochrane style) on green and blue open spaces and mental health, developed by a multidisciplinary expert working group, led by one of the authors, under the Horizon 2020-funded programme EKLIPSE.

In the second phase, the research designed the protocol for the development of the case studies [12,13] and applied it to two different cities. The case study was selected as the method to undertake this part of the work as it allows investigating the phenomenon under study, in relation with its urban context, using different sources of evidence. Field research was conducted focusing on the analysis on cities that have already demonstrated good capacity to integrate biophilic design at multiple scales, i.e., cities with good potential to innovate and with more financial, technical, and institutional capacity and experience 
in running regenerative architecture and urban projects. The objective was to understand the level of integration of biophilic design, the theoretical foundation, and the policy, and implementation process for this, as well as drivers and limitations. The selection of cities was based on the following criteria: (1) focusing on two cities for different biophilic design scales, i.e., workplace, neighborhood, city; (2) sufficient secondary sources to develop the analysis; (3) availability to conduct interviews to designers, public servants, and/or other stakeholders. The cities selected for the development of the case studies were finally London and Chicago.

For London, field research was developed by the authors also within the wider scope of working group activities of the COST (Cooperation in Science and technology) Action "RESTORE Rethinking Sustainability Towards a Regenerative Economy", in the period 2017-2020.

For Chicago, key stakeholder interviews and media and policy analysis were conducted, in the period 2016-2019, as part of a larger project on Chicago's urban greening, climate change, and resilience initiatives. The Resilient Corridors project emerged as a pilot in 2019 from the City of Chicago.

\section{Theoretical Frameworks on Health and Nature}

\subsection{Adaptive and Utility Paradigms}

The link between access to nature and human health benefits is supported evidence accumulated over the last 40 years [14-18]. This has been of interest to designers who include access to nature for its diverse benefits, such as in the workplace [19], and city planners who are interested in the socio-cultural benefits of green infrastructure for human health and well-being [20,21]. Although the evidence points to clear benefits between access to nature and human health outcomes, there remains a lack of alignment between this large body of research and the type of evidence that convinces stakeholders that adding nature will reap tangible and trackable benefits for their unique project [11]. This misalignment is partly due to the types of research-and the paradigms that support them-that undergird the vast majority of findings that have gotten the attention of policy makers and building owners. Furthermore, these types of research tend not to align with the more holistic approach of designers using a biophilic framework [11,22].

Comparing research on nature is complicated by the wide variety of types and measures used, which can complicate the establishment of robust results between them [23]. The most influential research programs in the last forty years have been based on adaptive or utility paradigms. The adaptive paradigm is based on the assumption that evolution, or biological survival, motivates physiological and psychological responses to the experienced environment, and that some environments are better suited to human health and well-being than others. There are two research programs that have emerged out of an adaptive paradigm that have garnered the most attention and subsequent research. The first focuses on restorative environments that help with the restoration of attention or to improve cognition, notably Stephen and Rachel Kaplan's Attention Restoration Theory (ART) $[2,24]$. The second focuses on the ability of restorative environments to support stress recovery and positive mood, notably Roger Ulrich's Psychophysiological Stress Reduction Theory (PSR) [25].

The original ART research argued that nature possesses four attributes necessary to hold our attention involuntarily and be experienced as restorative: fascination, mystery, coherence, and the feeling of being away, and this research has been heavily tested in subsequent studies $[24,26,27]$. A key component of research testing ART has looked at aesthetic preferences for different types of nature. These studies argue that some types of nature are more favorable to restoration than other types of nature, and that nature overall is more restorative than urban environments $[10,17,24,28]$. Research testing the PSR theory also uses an evolutionary biology theory but tends to focus on the affective or emotional aspects of this relationship. At its core, evolutionary biology argues that because we evolved in nature, we tend to feel connected with things that remind us of nature; this 
attitude is called biophilia (translated as a love of nature) $[25,29]$. This love of nature has begun to be studied for its potential to link to our connectedness to nature, which has been shown to improve health and well-being outcomes as well as sustainability behaviors and belief in climate change [30-35]. While the utility paradigm also draws on the idea that our natural environment is connected with our well-being, it focuses on the role that nature plays as a quality of an environment to satisfy current personal or interpersonal needs. These are often measured by known benefits of access to nature, such as increased levels of physical activity, restorative experiences, or social cohesion, interaction, and safety [36-38].

\subsection{Understanding Nature-Health Research through the Adaptive and Utility Paradigms}

The adaptive and utility theories underlie the vast majority of research linking access to nature and improved physiological and mental health and well-being. Some researchers have continued to develop these theories and have proposed that these relationships can be viewed as a series of pathways that have formed the basis of multiple research streams: (1) stress reduction, (2) physical activity, (3) social cohesion, and (4) air quality [15]. Understanding the key types of research on the benefits of nature and the aim of these research streams can help designers and planners determine which research is relevant to their project goals.

Stress reduction has traditionally received the most empirical and theoretical attention. Research looking at stress reduction has tended to follow the ART and PSR restoration theories outlined above. These two theories rely mostly on the visual and aesthetic qualities of nature, and they link to the assumed characteristics of nature seen in evolutionary and related biophilia (or biophobia-fear of nature) theory [25,39]. While the variety of contexts for this research supports the strength of the research, it has been harder to evaluate their application at a building scale given the high number of variables involved.

Physical activity has been gaining attention and follows the utility paradigm. As opposed to sedentary behavior, outdoor physical activity has been shown to have positive effects on mental health, showing for example better outcomes in green areas than indoor, or non-green urban areas [40]. However, the results have been unclear in cross-sectional and/or epidemiological studies at the neighborhood scale [41], showing the difficulty of applying lab-based studies to real-world situations. Real-world situations have other explanatory variables that may influence health outcomes. Furthermore, lab-based studies do not always take into account other factors such as green space characteristics, location, and other influences, or mediators, on behavior or preferences. Studies have found that multiple factors over and above the amount of greenspace-including quality and accessibility - determine urban greenspace use and physical activity [42-44].

The third pathway looks at how access to nature is linked to improvements in social interactions (at the individual level) and social cohesion (at the neighborhood level) and varies in its research paradigms - ranging from utilitarian, which focuses on characteristics of parks that influence desired uses, to the design of parks, which influences social cohesion [45]. Although the link between social interaction and mental health has been firmly established [46], the link between social interactions, social cohesion, and green space has received less research attention than the first two pathways.

The research linking air pollution, nature, and health has equally received less attention. While the link between air pollution and negative effects on physical health and mortality has been long established [47], newer studies have also linked air pollution with negative impacts on mental health [48], and cognitive performance [49]. Some researchers have gone further and proposed that air pollution, together with traffic-related sounds, can put a constraint on the restorative potential of an environment as a whole [50]. This holistic approach is important for understanding negative environmental influences or ecosystem disservices. This last pathway can be one of the most easily integrated into regionallevel planning and regenerative policies and can be a good way to balance synergies and trade-offs at this scale. 
Lastly, the concept of Topophilia [51] has received renewed interest recently among planners, designers, and academics in Europe, who see the focus on personal identity and meaningful attachment with place and landscapes as a powerful design tool for reconnecting urbanites with local nature and thus inspiring sustainable behavior. While in theory, place attachment can be used to inform a regenerative approach to urban and regional planning, it has not been used much in application to date due to its more theoretical and qualitative approach and the lack of alignment with design and planning practice.

While there has been some qualitative research conducted in the adaptive and utility paradigms, the vast majority of this research follows a psychometric research approach, which aims to generalize relationships through quantifiable measures [52,53]. The psychometric approach aligns well with the kind of data promoted by urban planning and green building researchers and has created a vast amount of data on the benefits of access to nature (outlined below). It has also been very influential in public policy $[54,55]$ and has provided much of the support for adding nature into buildings, neighborhoods, and cities to date. However, the type of linear and somewhat mechanistic approach to nature and health in psychometric research does not always align well with the more holistic, design-thinking approach seen in biophilic design and green infrastructure work to support human health. There has also been some criticism from social scientists that research based in the adaptive paradigm tend to not address the larger context of place and that the underlying evolutionary paradigm-i.e., that love of nature is innate-can hide cultural, socio-economic, and power differences that can influence the success of urban nature interventions and the equitable access to nature. The utilitarian paradigm has also been criticized for its limited understanding of the socio-economic and socio-cultural factors influencing access to nature, the reduction of environmental values to utility, and the general lack of acknowledgement of the symbolic aspect of nature [56]. In short, while research following the adaptive and utility paradigms have provided strong evidence to support the health goals of biophilic design, biophilia's focus on sense of place, lived experience, and holistic design-thinking may be more aligned with some of the relational and sense of place work on the human relationship to nature that rarely gets cited [57-59] outside of academia.

\subsection{Research to Practice: Design Theory, Research, and Application}

One of the most commonly understood "popular" urban greening and design approaches is biophilia. Popularized by the biologist E. O. Wilson's biophilia hypothesis, which prompted the modern biophilic design movement, biophilia is defined as the " $[\ldots]$ innate emotional affiliation of human beings to other living organisms. 'Innate' means hereditary and hence part of ultimate human nature" [22] (p. 31). Kellert and Wilson operationalized this concept to the built environment [39], and it was further developed in Kellert's proposed attributes for biophilic design [60], where he introduced key dimensions, elements, and attributes of biophilic design. As two main dimensions, the author identified organic/naturalistic and place-based/vernacular. Organic dimension refers to "shapes and forms in the built environment that directly, indirectly, or symbolically reflect the inherent human affinity for nature" [60] (p. 5). Vernacular dimension refers to "buildings and landscapes that connect to the culture and ecology of a locality or geographic area" [60] (p. 6). Further classifications refer to six main elements, which then break out into more than 70 biophilic design attributes. These attributes can be as simple and straightforward as the presence of water, air, sunlight, plants, animals, as well as more articulated, such as sensory variability, information richness, exploration and discovery, or geographic, historic, ecological, and cultural connection to place. Importantly, biophilic designers need to understand that the environment can be an atmosphere, a process, an experience.

There have been some further revisions to Kellert's work, an example of which is Terrapin Bright Green's 14 Patterns of Biophilic Design-Improving Health and WellBeing in the Built Environment. This report [61] defines 14 patterns of biophilic design organized into Nature in the Space, Natural Analogues, and Nature of the Space Patterns. 
Another is the Biophilic Interior Design Matrix [62], which adopts and adapts Kellert's work to operationalize it for interior environments, in order to provide tangible and clearer guidance for designers.

\subsection{Experimental Biophilic Design Approaches}

In addition to more traditional biophilic design, alternative approaches strive to explore biophilic principles, ideas, and attributes in more experimental, even esoteric ways, trying to grasp the essence of human experience of space and model it in line with biophilic principles. Design, and architecture in particular, has been called a hybrid discipline, relying and building upon different elements within science, technology, and art [63]. This is in direct conflict with many of the quantitative and linear approaches favored by many researchers. Not all qualities of architectural space can be quantifiable and not all qualities of our experience of space can be translated into rational language. The process of developing space for designers and architects is that of an artist providing experience and hopefully emotional attachment.

One of the foremost thinkers in experimental biophilic design is Juhani Pallasmaa, who explores the art of building, elements of architectural experience, and meaningful spaces that stimulate people and provide existential encounters. Key components of his work include the experience of architecture through mental and physical frameworks which shape our identity, attachment, and sense of place. He argues that the mental component of experience has been widely neglected "in the field of architecture ... where scientific criteria or methods have mainly been applied in its technical, physical and material aspects, whereas the mental realm has been left to individual artistic intuition" [63] (p. 4). He hopes for neuroscience to provide a deeper understanding of the mental implications and impacts of "the art of building". Pallasmaa also argues that our architectural experience is multi-sensory, and we experience architecture with our physical, emotional, mental, and social bodies, and that environments have the potential to stimulate our imagination and identity. Pallasmaa argues that the architectural attributes of hierarchies, information richness, order and complexity, affection and attachment, attraction and beauty, reverence, and spirituality [60], are all attributes that are also in biophilic design, and that they should be studied following an artistic and scientific approach.

Some of the limitations of the adaptive and utilitarian approaches to nature-human research may be addressed by Pallasmaa's suggestion of a biological historicity approach. This approach blends sense of place and biological and historical aspects of the place. For example, sense of place as an attribute does not rely only on biological, geographical, or natural features of the place but also on its historical layers, site-specific social developments, and cultural layers embedded in its core. These include historic and cultural connections to place, the integration of culture and ecology, age, change, and the patina of time [60]. Biophilic design addresses some of the gaps in adaptive and utilitarian research by acknowledging these social and cultural dimensions of places. Pallasmaa calls this a bio-psychological heritage, which-he argues - particularly influences the qualities of refuge and prospect, which are key factors in the evolutionary approach to the benefits of access to nature for humans [63]. Pallasmaa also connects biophilic attributes such as fear and awe [60] to the pleasure principle, which understands our experience of space through the dichotomy of pleasures and displeasures that drive our behavior and perception of space. Combined, these experiential approaches to the experience of space and design have the potential to create a more embodied and place-based understanding of the impact of biophilic design and access to nature on our health well-being and sense of place, which may help foster better nature-human connections, attachment, and a sustainable ethos. 


\section{Mainstreaming Biophilic Design: Research, Design, and Practice}

How cities can build resilience has become a major undertaking and priority. It requires cities to address a variety of pressing global and local challenges through multifunctional strategies, including climate change, community health, economic downturns, and political uncertainty.

The integration of evidence-based research and design on nature and health has already proved to be successful toward these long-term goals, but it requires a genuine acknowledgement and a deep understanding of how it can be applied at different scales. This is particularly true when attempting to align, in policy and practice, buildinglevel, neighborhood-level, or city-level initiatives with community resiliency or climate change measures.

As a reminder, a taxonomy of biophilic elements can be identified at three main levels (Table 1).

Table 1. Taxonomy of biophilic elements. Adapted from [64].

\begin{tabular}{ccc}
\hline Scale of Biophilic Design & Forms of Biophilic Elements & $\begin{array}{c}\text { Taxonomy of Biophilic } \\
\text { Elements }\end{array}$ \\
\hline Building scale & $\begin{array}{c}\text { Green roofs, green walls, } \\
\text { shade trees, vegetation, and } \\
\text { natural elements inside and } \\
\text { around the building }\end{array}$ & $\begin{array}{c}\text { Green roofs, green walls, shade } \\
\text { trees, vegetation, and natural } \\
\text { elements inside and around the } \\
\text { building }\end{array}$ \\
District and neighborhood \\
scales & $\begin{array}{c}\text { Street trees, pocket parks, } \\
\text { orchards and community } \\
\text { gardens, business parks }\end{array}$ & $\begin{array}{c}\text { Many installations, } \\
\text { small-medium in size, } \\
\text { restoration possible, high } \\
\text { technical and technological } \\
\text { requirements, public and } \\
\text { private properties }\end{array}$ \\
\hline City scale & $\begin{array}{c}\text { City parks, urban forests, } \\
\text { urban agriculture, waterfronts }\end{array}$ & $\begin{array}{c}\text { Few installations, large in size, } \\
\text { restoration possible, high } \\
\text { technical and technological } \\
\text { requirements, public land }\end{array}$ \\
\hline
\end{tabular}

The selected case studies demonstrate the application of research and design practices on the benefits of nature in cities and will be followed by a discussion of limitations and suggested next steps. The first two use biophilic design, while the third uses a more socio-ecological approach to the benefits of nature. In order to support the relevance of a multiscale design investigation and related knowledge transfer from research to practice and policy, the implementation of "informed" biophilic design is illustrated in the following sections describing a research study conducted in the City of London, which is focused on biophilic implementation at different scales. The emphasis is on the value of biophilic design principles for people and the lived environment in application at multiple scales for regenerative design and community resilience.

By 2041, the population of London is forecasted to reach 10.3 million people, which is an increase of 1.2 million people when compared with 2019 [65]. London is also one of the greenest cities in the world [66]. All across London, a network of Royal Parks, pocket gardens, planted roofs, rain gardens, living walls, urban forests, community gardens, and street trees are greening the city, making its public spaces accessible, colorful, and vibrant places to visit, live, and work.

This nature is a vital part of the complex organism of the city bringing benefits right into the places where people work and live. Moreover, as London's population grows, and its neighborhoods experience more development, that will be more important than ever.

\subsection{Building-Scale Applications: Living Lab at the Shard, London}

With the growing research and interest focused on biophilic design, it is interesting to look at buildings specifically designed and constructed as a model to highlight the biophilic indoor attributes. 
DaeWha Kang Design has created an experimental work environment on the 12th floor of the Shard, in London, that has the express purpose of measuring the impact of biophilic design on worker wellness and productivity.

Working in collaboration with Mitie (the client) and Dr. Marcella Ucci (head of the MSc in Health, Wellbeing and Sustainable Buildings at the University College of London), the designers have designed a pilot study to measure the impact on employees through a detailed post-occupancy evaluation.

Biophilia, as said, refers to human beings' innate need for a connection with nature. Human physiology is wired to seek qualities of light, view, material, and other factors common in the natural world. This project comprises two spaces designed according to those principles: a "Living Lab" that functions as an immersive work environment, and two "Regeneration Pods" that provide short-term rest and meditation functions for the Mitie employees.

The Living Lab is fully immersive, with rich and intricate patterns, natural materials, and interactive dynamic lighting. The room gains privacy through bamboo screens that wrap onto the ceiling above. The floor, desks, and task lights are also formed from different shades and textures of bamboo, providing an organic language for the entire space. The lighting in the room is circadian and linked to an astronomical clock-cool blue in the morning, brilliant white in the afternoon, and fire-like orange as the day winds down. The light softly breathes, very subtly shifting intensity in an almost imperceptible way, giving additional dynamism to the experience.

In the study, Mitie employees worked at these desks for four weeks at a time, answering daily surveys about their comfort, satisfaction, and emotional response (Figure 1).

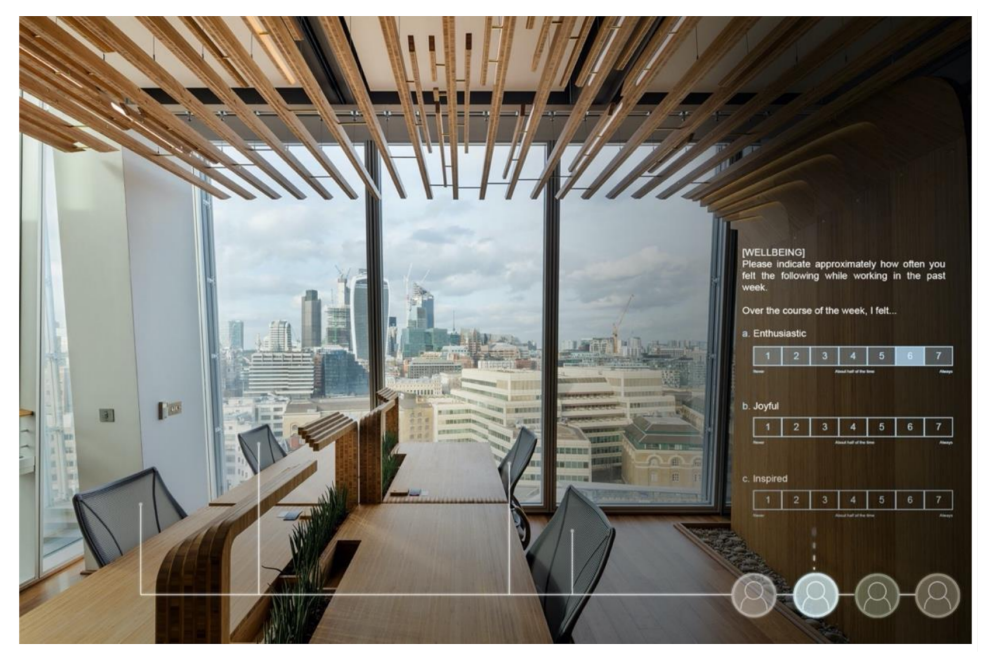

Figure 1. Post-occupancy evaluation at the Shard Living Lab in London. Photo by Kyungsub Shin, with graphics by DaeWha Kang Design. Courtesy DaeWha Kang Design.

Then, they spent four weeks working in a control area on the same floor with similar environmental conditions but without biophilic design, and their responses were compared between the two spaces.

While studies have established the positive impact of daylight, natural materials, and a direct visual connection with nature, aesthetic design also has a strong impact. The bamboo screens strike a balance between the regular rhythm of structural ribs and the variation and playfulness of discrete leaves that maintain a sense of transparency and intricacy in the space. The leaves catch natural light but also diffuse embedded lighting within the screen itself.

While the Living Lab creates a sense of enveloping enclosure toward the rest of the office, it opens up toward the façade, providing long vistas and a strong connection to the sky. The Shard has a high-tech aesthetic of glass and metal, and the warm bamboo palette of the Living Lab establishes a strong counterpoint to that material language. 
Mitie is one of the leading outsourcing and facilities management companies in the UK, and they have created a new "Connected Workspace" initiative that incorporates sensor technology, big data, and machine learning to revolutionize the way their portfolio of buildings is managed and maintained. The Living Lab was commissioned as part of the health, wellness, and user-experience aspect of Connected Workspace.

Following biophilic principles, the desks are originally crafted from natural bamboo and incorporate living plants directly into their workspace, and not only relevant technology. From a scientific point of view, achieving a meaningful experimental study on the users requires adapting for confounding environmental factors between the lab space and the control space, while on-desk sensors detect air quality, light levels, temperature, and humidity. An access card reader identifies the users and allows them to activate the task lights and charging strips, while an under-desk sensor records when they are actively working at the desk. All of these data are collected in Mitie's data lake and can be correlated with the survey results.

Direct access to living nature is also shown to have a host of benefits, and planters are organically integrated directly into the desks together with the task lights [67].

In the second section, the "Regeneration Pods" are once again constructed from bamboo, following Mitie's mental health and wellness initiative, providing a tech-free space for meditative moments within the workday. Similar to the "Living Lab", the bamboo construction provides a sense of shelter, while workers access the views outside. The routed featherlike panels slot into the seventeen identical spines, with minimal cross support. Upholstered seating is fitted within the spines, also with circadian LED lighting. Environmental sensors-monitoring light, movement, humidity, and temperature-were also integrated into the structures, making this an ambitious technical build for the architects and team and a good example of research-based design (Figure 2).

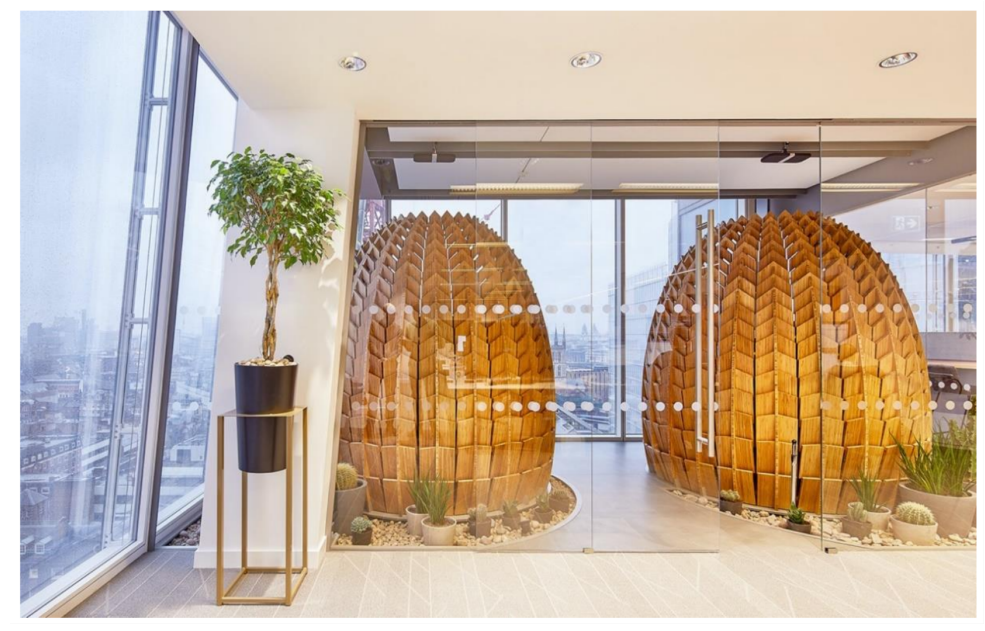

Figure 2. The "Regeneration Pods" provide a sense of shelter while workers access the views outside. Photo by Tom Donald for Aldworth James \& Bond. Courtesy DaeWha Kang Design.

\subsection{Scale Jumping: District- and City-Level Applications of Integrated Design and Research}

Looking next to the city scale, the translation of biophilic design interventions for human health and well-being, inspired and informed by research paradigms, is also found in the larger City of London.

Working together, the Mayor, Natural England, major landowners, and the wider business community, represented by Business Improvement Districts (BIDs), have recognized the increasing importance of biophilic planning and design principles (Table 2) for future-proofing the capital. 
Table 2. Attributes of biophilic design. Adapted from [68].

\begin{tabular}{ccc}
\hline $\begin{array}{c}\text { Direct Experience of } \\
\text { Nature }\end{array}$ & Indirect Experience of Nature & $\begin{array}{c}\text { Experience of Space and } \\
\text { Place }\end{array}$ \\
\hline Light & Images of Nature & \\
Water & Natural Materials & \\
Vegetation & Simulated Natural & Prospect and \\
Refuge \\
Animals & Light and Air & Organized Complexity \\
Weather Conditions & Naturalistic Shapes & Integration of Parts to Wholes \\
Natural Landscape & and Forms & Transitional Spaces \\
and Ecosystems & Evoking Nature & Mobility and Wayfinding \\
Fire & Cultural and Ecological \\
& Anformation Richness & \\
& Age, Change, and & \\
& Patina of Time & \\
\hline
\end{tabular}

\subsection{Urban Park-Scale Applications: Queen Elizabeth Olympic Park}

The Queen Elizabeth Olympic Park is one of the largest urban parks (102 ha) created in Western Europe for more than 150 years, which was designed by LDA Design in conjunction with Hargreaves Associates (2012), to enrich and preserve the local environment by restoring wetland habitats and planting native species of plants.

Its environmental features include the restoration of the River Lea, in the northern section of the park, the habitat-creation strategy, and the park's connection with its hinterland ecosystem. The landscape is dominated by native trees and flowering meadows of designed plant communities (Figure 3). "Flowing schemes are not arbitrary but have carefully thought-out shapes running through them: S-curves, lines of grasses, successive waves of plants, rising up through the season, anchor plants with satellites and fuzzy edges between one habitat and another" [69] (p. 24). Sensory and spatial variability, information richness, and natural shapes and forms encourage exploration, fostering sense of place and the human-nature relationship. Other elements and attributes of biophilic design include a lighting scheme designed by Speirs + Major, integrating natural light and shadows with filtered, diffused, or reflected light, all emphasizing spatial variability and harmony.

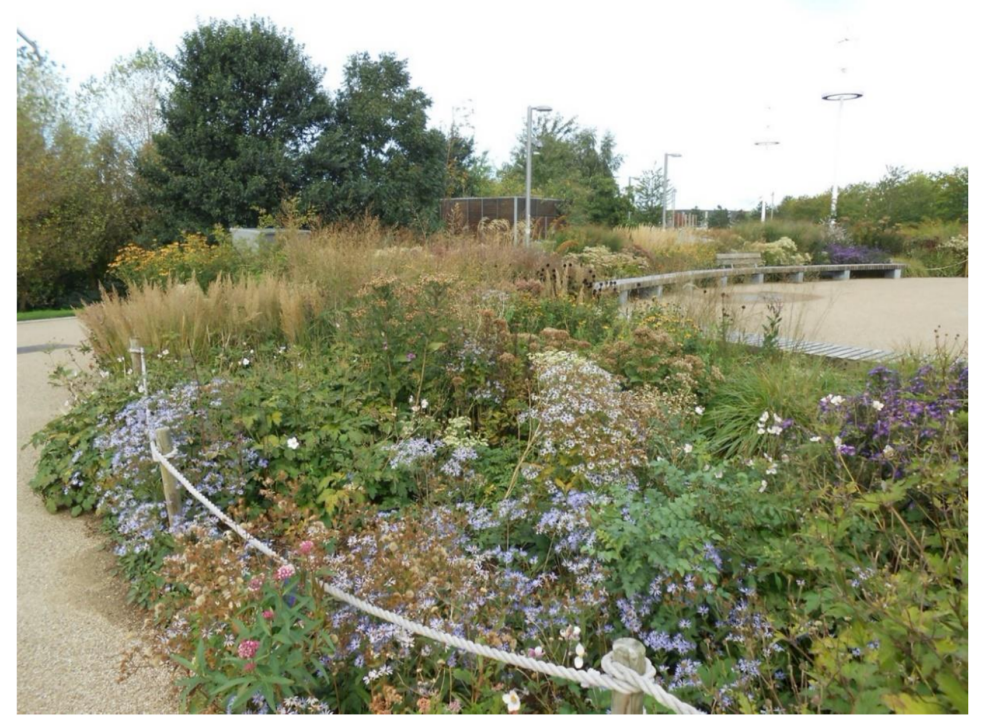

Figure 3. The European Garden at Queen Elizabeth Olympic Park, a distillation of the "meadow aesthetic": a visually dramatic, highly designed, and enhanced evocation of a wildflower meadow (Nigel Dunnett and Sarah Price). Photo by Maria Beatrice Andreucci. 


\subsection{District-Scale Applications: Greenwich Millennium Village}

Greenwich Millennium Village (GMV) is a mixed-tenure modern development on an urban village model, which is located on the Greenwich Peninsula, in Greenwich, in southeast London, and it is part of the Millennium Communities Programme, under English Partnerships. GMV was originally designed by visionary architect Ralph Erskine as part of the regeneration of the whole brownfield site of East Greenwich Gas Works. The whole district landscape considers wildlife in the design of the soft estate around the built forms, through choice of species and inclusion of artificial refuges, in appropriate locations and numbers.

In particular, the Ecology Park is an exemplar of biophilic and biodiverse design, providing a significant boost to the value of the GMV in terms of exploration/discovery, affection/attachment, security/protection, and attraction/beauty. An Ecology Park Centre manages biodiverse areas of Southern Park as well as new habitats associated with future developments (Figure 4).

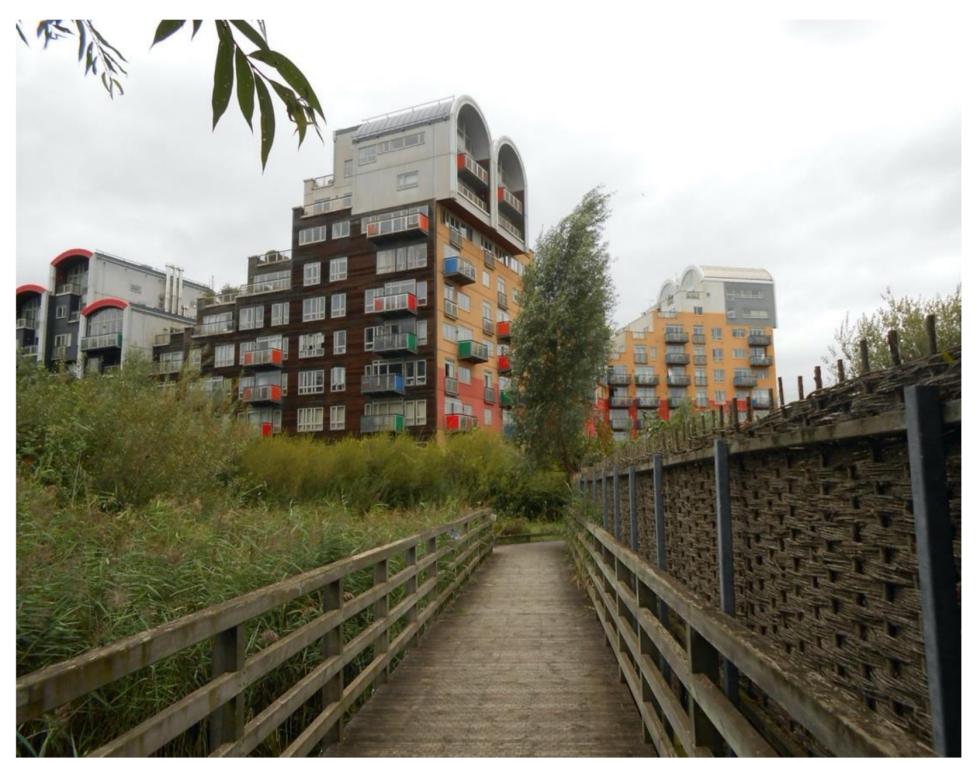

Figure 4. The biophilic features of the Greenwich Peninsula Ecology Park has been playing an important role in the area's regeneration and community life since its creation in 2002. Photo by Maria Beatrice Andreucci.

Greenwich Peninsula and GMV offer to residents and visitors alike multiple connections to place-i.e., historic (Maritime Greenwich heritage site), geographical (the Prime Meridian of the world, Greenwich Mean Time, and the Observatory), cultural (colleges and universities, artworks, museums, etc.), and ecological (Ecology Park)—fostering placebased relationships.

\subsection{Neighborhood-Scale Applications: The Barbican}

The Barbican is Europe's largest arts and conference complex, and it also includes a significant residential community. It is a noted example of uncompromising modernist architecture, built mostly in the 1970s. The original design aimed to create a self-contained "urban village", with the residential and public spaces separated completely from vehicle traffic. Most of the landscape elements, including the water bodies, are "podium landscapes" or "landscapes above structure": roof gardens and green roofs, with car parks, the arts complex, and recreational facilities beneath [69]. In 2013, following re-waterproofing of the roof gardens, the opportunity arose for completely new plantings to be installed. The new design takes a radically different approach. The concept for The Barbican plantings is to create continuous and successive waves of color over long periods of time through orchestrating a series of dramatic color washes over the entire site, from spring through 
to late autumn, and then to finish off the year with a textural array of seeds heads, plant structures, and foliage. Although the plantings are very diverse, at any one time, there are only two or three plant species that create the main flowering display. However, these species are repeated over the whole area, creating maximum impact. Planting in layers allows for one set of plants growing up and through the preceding set of plants, leading to a continuous succession. Naturalistic swathes of perennials and grasses are framed and contained within clumps, groupings, and scatterings of multi-stemmed trees and shrubs to give solidity and a three-dimensional framework throughout the year [69].

There is no precise planting plan for most of the species, but the proportion of each species in a mixture is carefully considered, and the plants are placed within the planting areas according to a set of rules and instructions aiming at replicating natural patterns and processes. Plants that are adapted to extreme dry conditions often have gray or silvery leaves (Figure 5), and there is a natural unity to plantings that comes from bringing plants together from similar habitats [69].

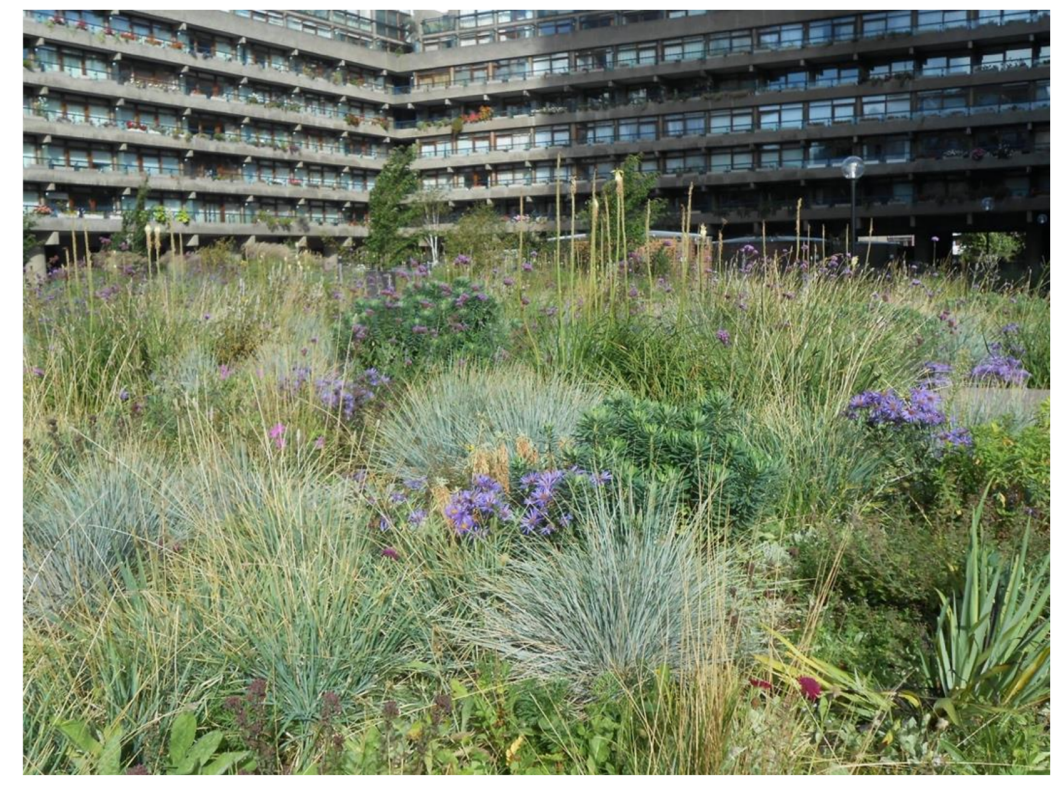

Figure 5. The "shrub steppe" plantings at the Barbican combine mixes of perennials and grasses to the steppe plantings, with additional low-density shrubs and multi-stemmed trees, to create multi-layered plantings with year-round structure and interest. Photo by Maria Beatrice Andreucci.

\subsection{Community-Scale Applications: Mudchute Park and Farm at the Isle of Dogs}

The Mudchute Park and Farm was established by the local island community. Originally, it was a piece of derelict land created during the last century from the spoil of construction from dredging Millwall Dock. For decades, Mudchute environmental features, natural patterns, and processes remained untouched. However, in 1974, the site was earmarked by the Greater London Council for the construction of a high-rise estate. The resulting public campaign against these plans reflected the affection that local people, and those working on the island, felt for the Mudchute. Their success secured it as the "People's Park" for the area. In 1977, the Mudchute Association was formed to preserve and develop the area. Farm animals and horses were introduced, trees and plants were planted by generous volunteers and corporate teams, and the educational benefits of the area were also recognized. Local schools are encouraged to use the project to study the natural world on their doorsteps (Figure 6). Since the establishment of the association, the Mudchute has steadily built a reputation for providing place-based relationship and direct nature experience through a variety of educational and leisure activities, on a London-wide basis. 


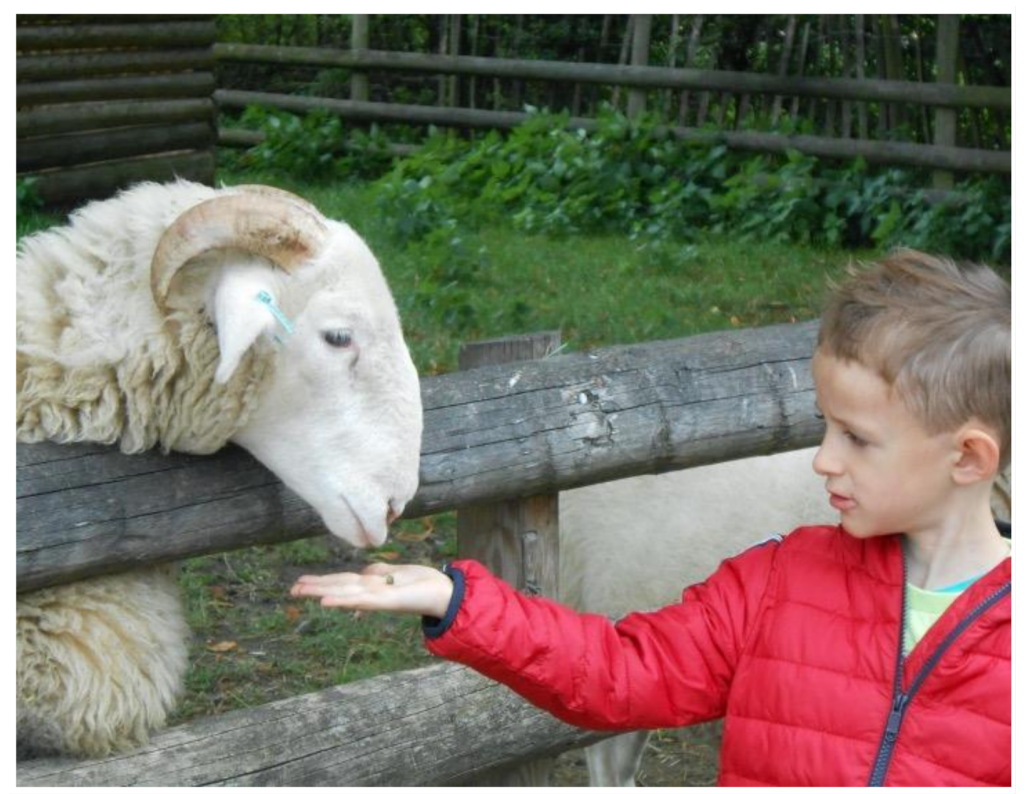

Figure 6. School children are encouraged to experience the "biophilia effect" at Mudchute Garden and Farm. Photo by Maria Beatrice Andreucci.

4.7. Exploring Multi-Sensory Experiences through Experimental Biophilic Design: Olafur Eliasson at Tate Modern

Attempts to humanize architecture through the exploration of issues such as multisensory experiences and human perception, physical and psychological boundaries, the role of imagination and empathy in space, and the pleasure principle can provide very effective experiences of biophilic design in space.

One example is the practice and work of Olafur Eliasson, a Dutch-Islandic artist who is fusing many disciplines into his explorations of the human-nature-built environment nexus. Similar to many researchers who explore sense of place [70], he is concerned with phenomenological experiences. Eliasson is an artist, but he could also be called an architect, as many of his works are immersive environments with ephemeral spatial qualities that question perception, trigger the senses, and create a feeling of temporary community between people experiencing the environment (Figure 7).
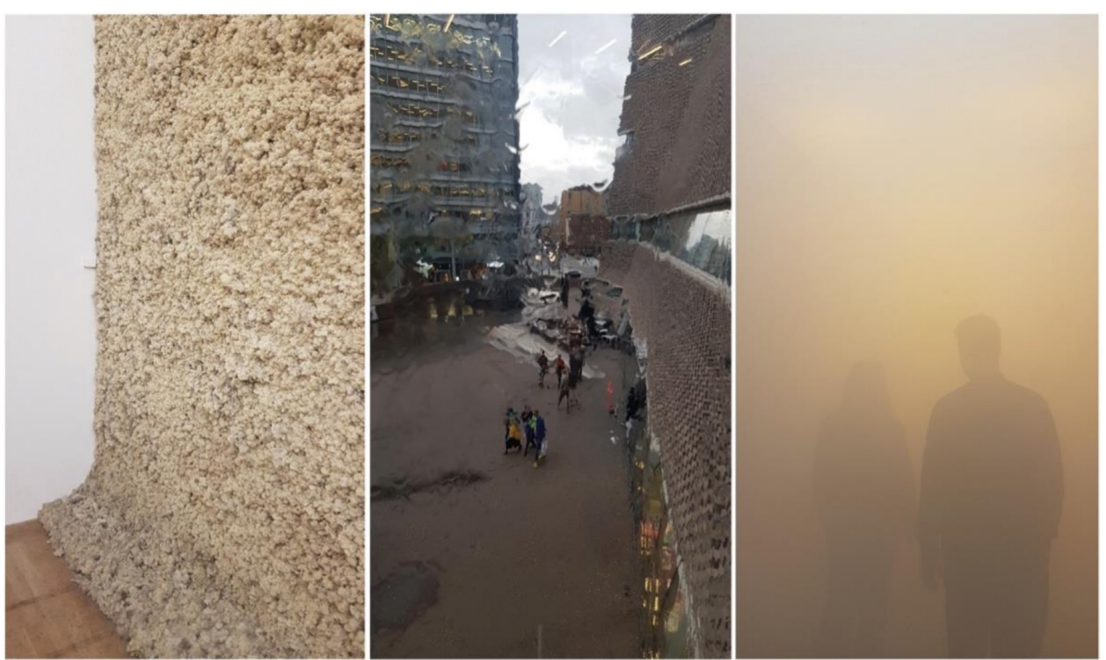

Figure 7. (left) "Moss Wall" (1994), (middle) "Regenfenster" (1999), (right) "Your Blind Passenger" (2010), artworks by Olafur Eliasson, exhibited at "In Real Life" exhibition, Tate Modern, 2019. Photos by Jelena Brajković. 
Of relevance for biophilic design, his work contains many biophilic principles and attributes, such as affection and attachment, attraction and beauty, and reverence and spirituality. His spaces also include transitional spaces, a dynamic balance and tension, and generally, almost all attributes outlined by Kellert in his principles of biophilic design [60].

\subsection{Linking Resilience with Social Justice and Economic Revitalization: Learning from Chicago}

Similar to many cities, Chicago faces environmental challenges linked to climate change, such as increasingly hot summers and flooding from heavy rain and older stormwater systems [71]. After the heatwave of 1995, in which over 700 people died, many of them low-income and people of color [72], Chicago has undertaken a series of initiatives to increase the environmental and ecological resilience of the city. While some of these initiatives - such as the beautification of key boulevards with seasonal flowers-were more focused on economic neighborhood revitalization than ecological goals, many of the initiatives combined urban greening with ecological resilience. Key initiatives include their Building Green Matrix (now called Sustainability Development Matrix), which required nature-based design choices for projects in select neighborhoods, extensive use of TIF (tax incremental financing) at the district scale to incentivize sustainability, and urban revitalization projects in both high-profile (Figure 8) and disadvantaged neighborhoods, greening alleyways (Figure 9) that replaced pavement with permeable pavement, and their signature green roof program, supported by their Sustainability Matrix, which led them to be North American leaders in green roof implementation for over a decade $[71,73,74]$.

These initiatives have been supported by larger policy plans, such as their 2015 Climate Change Action Agenda, their stormwater management plans [75,76], and their nomination as one of Rockefeller's 100 Resilient Cities, and subsequent resilience plan $[11,73,77,78]$. These policy plans regularly cite evidence of benefits of nature from research programs, which tend to use an adaptive and utilitarian paradigm. However, concerns about equity have meant that they have needed to also address social and economic aspects of urban nature. Chicago has also implemented a vacant lot revitalization and neighborhood stabilization plan, as well as a creative re-use of an abandoned elevated railway into a linear park, thus supporting active transportation that connects lower-income neighborhoods, in the west of the city, with wealthier neighborhoods, closer to the lake, in the east [79-82].

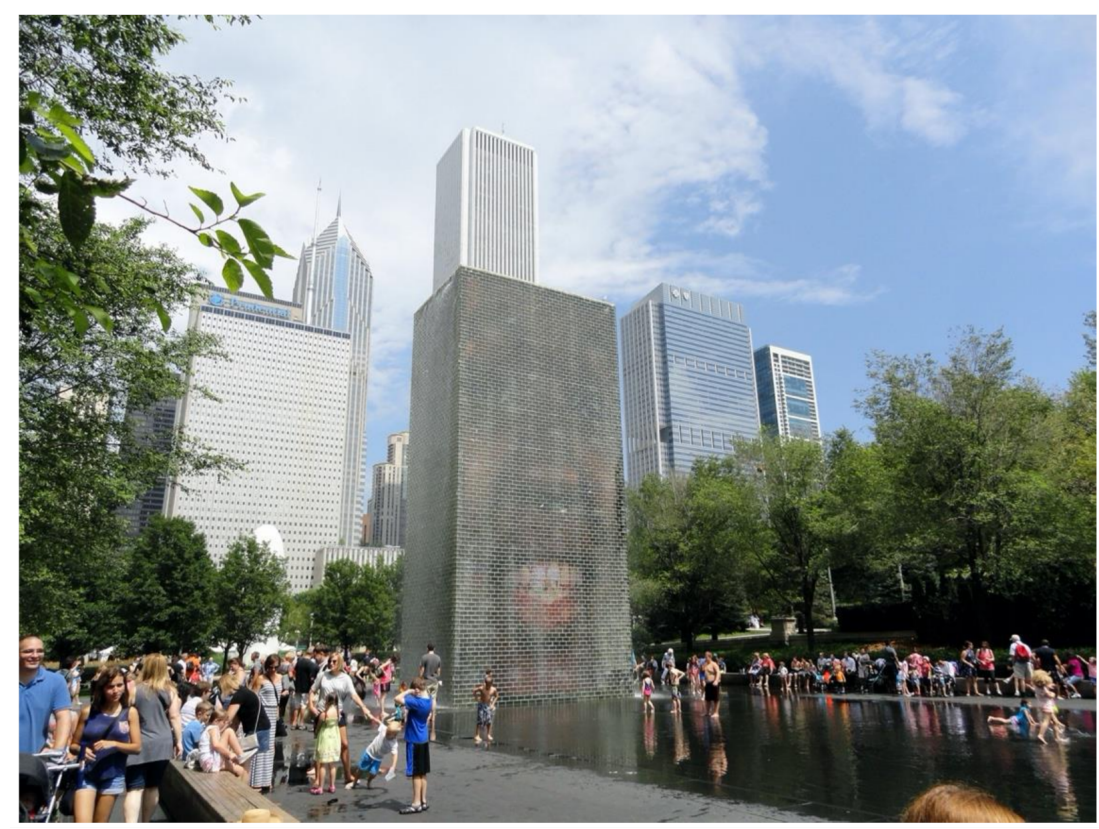

Figure 8. Crown Fountain, an interactive work of public art and video sculpture featured in Chicago's Millennium Park, in the Loop community area. Designed by Catalan artist Jaume Plensa, it features themes of dualism, light, and water. Photo by Maria Beatrice Andreucci. 


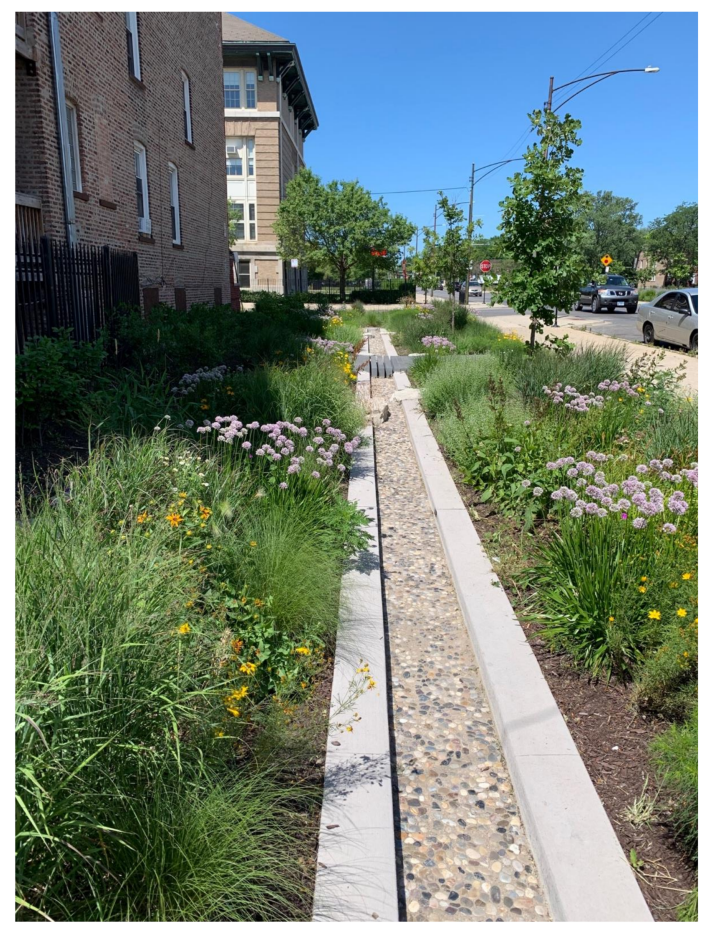

Figure 9. Resilient Corridor stormwater street-level feature, Chicago. Photo by Michael Berkshire.

Despite the leadership of a neighborhood association, the involvement of a non-profit who did extensive stakeholder engagement, the inclusion of equity goals and artist's work, and the provision of a safe bikeway for active transportation, along a busy corridor, there have still been complaints that the project has spurred gentrification and is potentially displacing some of the more vulnerable residents in the eastern end of the 606 trail $[83,84]$. While this has been challenged by some groups involved in the project, who have claimed that such a large investment is an easy target for larger-scale gentrification forces, it is still a good example of the challenges of implementation for cities wishing to balance ecological, social, and economic goals in urban greening projects. It is also a good example of the need to include social and economic values into any discussion about ecological or regenerative urban initiatives.

The City of Chicago is a good example of a new hybrid approach to urban greening and is well aware of these challenges. For some of these projects, city administrators have deliberately framed them as urban stabilization projects, instead of environmental projects in economically distressed neighborhoods and have worked hard to ensure that their work on resilience, and the resulting Resilient Chicago plan, define resilience as inclusive and incorporate economic and social resilience into any environmental agenda [73,85]. One of the most innovative urban greening projects to come out of Chicago recently balances ecological, social, and biophilic goals. It is an instructive case study on how to use stakeholder engagement and collaboration to fill some of the gaps outlined above, which are typical in nature-health research approaches, from adaptive and utilitarian paradigms.

In 2015, after Hurricane Sandy, there was a significant amount of funding available to municipalities to address resilience and adaptation for extreme weather events. The City of Chicago began to examine which areas in the city had a combination of the most vulnerable populations and extreme weather, looking at sociodemographic data, health data, street and basement flooding, and urban heat island areas, finding that many disadvantaged neighborhoods, in the south and west of the city, suffered from extreme weather events as well as health and economic disadvantages. Learning from their experience in previous urban greening and environmental projects, they held a series of meeting organized by a local non-governmental organization (NGO) to discuss where the biggest issues were with the communities. They applied for funding for using green infrastructure, such 
as stormwater management, bioswales, green roofs, etc. as a strategy to address both vulnerability and extreme weather issues with the funding. While their application in that round was unsuccessful, in 2017, there was another found of disaster relief money called the Community Development Block Grant (CDBG), which they repurposed the project for, and they were successful. The City argued for using city-owned vacant land and turning them into storm water management landscapes, similar to what the City of Philadelphia had been doing [86,87].

The project builds on a 2008 stormwater ordinance that requires projects to keep half an inch of rainwater on site or increase the permeability of the site by $15 \%$-thereby reducing both volume and rate of stormwater flow, which aligns with their Sustainability Matrix, which awards points for exceeding the stormwater ordinance requirements [87]. The project uses traditional green infrastructure strategies, such as permeable pavement, bioswales, and rain gardens, in combination with large underground storage and filtering strategies to drain stormwater from surrounding streets and alleys into these new landscapes, thus getting water out of people's basements. There are multiple linked parcels of land in the project, including three corridors, ten distinct projects, and 23 formerly city-owned vacant parcels, but the one with the strongest biophilic attributes is the parcel on 16th street (Figure 9). Of particular interest for the implementation of ecological, biophilic, and equity goals is the collaborative and ecological approach taken by the City. The City worked very closely with community groups, whom the City had previous experience working with, and who had the ability to help manage the projects. The City provided the community groups with a list of possible plants but let the community groups chose the plants and trees, and they collaborated extensively on the goals and design of the projects. The final project combines a nursery, green roof on an affordable housing project, and a runnel between the street and sidewalk, where the runoff will drain. The runnel blends big rock outcroppings in a serpentine pattern that crosses over the runnel so that children going to school can walk on the outcroppings and cross the runnel, mimicking a forest creek. The combination of interacting water features, community engagement, and native plantings is a good example of blending biophilic design with ecological and community-benefit goals.

The City collaborated with local neighborhood groups on a maintenance and stewardship plan, which is often a weak point with urban greening projects, and even hired locally for the installation [11]. They estimate that the entire Resilient Corridors project will provide over half a million gallons of storage of rainwater, lowering the level of water in the combined sewer area by 0.2 to 8.2 inches, and reducing the risk of basement flooding of almost 600 buildings in the area [87]. The project won an American Society of Landscape Architects (ASLA) award in 2018 [88]. While research on the outcomes of the project is ongoing, initial responses from the community have been very positive, with one resident commenting that she "couldn't believe they were doing this for them, that they listened to them, that they are getting exactly what they wanted, and that it is beautiful" [87] (p. 87).

\section{Discussion}

\subsection{Understanding the Application of Research to Practice}

The review of the two key paradigms underlying most research programs on nature and human health highlighted the strengths and limitations of these initiatives, emphasizing their easy transfer to policy, due to their psychometric methods, but also their tendency to miss socio-cultural and power dynamics of place. The conducted study also pointed to the disconnect between the design and lived experience of place goals of biophilic design and research programs used in policy as well as new directions in somatic experience of place that can be used to connect urbanites to biophilic design.

The case studies exemplified the translation of research to practice, and the use of a diversity of evidence in real-world contexts. The City of London case study represents a good example of what kind of research can be applied to which context, supported by several applications at different scales. The translation of research to practice at a building scale could benefit from a critical analysis of which studies can be applied to the workplace 
and why, combined with an attention to biophilic design principles and a sense of place. At a larger scale, urban parks, wetlands, and community gardens in London's initiatives can help achieve ambitious goals to green and re-wild the city for people and nature. These implementations represent "an acknowledgement to how vitally urban lives are bound up with and enriched by nature" [89]. The City of Chicago Resilient Cities project is equally an innovative example of bridging research and practice while envisioning a more resilient and just neighborhood through green infrastructure and biophilic design principles. It blends known research on the benefits of access to nature and lived experience of place with active and adaptive collaboration with community partners, so that the new "place" is both ecologically and socially important to the community while addressing real climate change and economic vulnerabilities.

The discussion below draws on the insights of the different research paradigms, design practices, and case studies, aiming to provide key lessons learned that designers and planners can apply to their practice.

\subsubsection{Benefits of Nature in the Workplace}

One of the outcomes of great interest to business and industry is the potential improvement in human performance from access to nature in the workplace. However, biophilic design, which translates research to practice, has been criticized for not linking specific studies to specific design outcomes. One way to do this is to examine which studies address the desired outcomes and then analyze if they can be applied to the context of the design intervention. Multiple studies have shown improved task performance from access to nature, which is measured often through cognitive tests and proxies for productivity. These studies have been criticized, in turn, for not replicating the actual day-to-day tasks of office workers, and there has been limited research done in situ for office workers.

However, the benefits of improved task performance from better concentration are supported by multiple studies in nature $[90,91]$. These studies should not be used alone to prove increased performance from biophilic design interventions, due to limitations in how performance is measured, its applicability to different types of work and workplaces, and a lack of research specifically looking at nature, performance, and the workplace. However, if studies showing improved concentration from access to nature at multiple scales are combined with other performance measures, at an individual and organizational level, such as absenteeism, or commercial output—such as at the Living Lab at the London Shardthey can provide a reasonable indication that design interventions that increase access to nature for workers will likely lead to improved cognitive function and performance in the workplace.

\subsubsection{Biophilic Design and Mental Health}

Getting out of buildings, into natural green space, walking, or forest bathing, has long been recognized as beneficial and a prescribed option for general practitioners. Even observing the ordered complexity of fractals, which are self-similar scales found within nature, can reduce stress [92]. This is a key relief that is especially needed during Covid-19.

Covid-19 has highlighted the role of nature in mental health and socialization [6,7]. We have been forced to slow down and pay attention to nearby nature and value the role it can play in our mental health and well-being. Urban parks, or the lack thereof, are making headlines for their role in nurturing quarantined people's mental and physical health [8]. Throughout the lockdown, governments, regional and city officials have recognized the importance of space, from country parks, to city parks, urban green spaces, as vital for physical and mental well-being.

The (re)discovery of the joy and refuge of nature, specifically local nature on doorsteps and in backyard gardens, has led to newfound delight in fractal minutiae around us and a slowing down of the pace of urban life. This slowed pace-at the core of neighborhood projects such as The Barbican and GMV, in London-may be key to mainstreaming the restorative benefits of nature. 
5.1.3. Biophilic Design and Connectedness to Nature: A Tool for Environmental Behavior Change

This review proposes biophilic design as a possible framework or pathway to connecting humans with nature through design that encourages sensory contact, emotion, meaning, beauty, and compassion, and which builds on the biophilic elements from Kellert. This is aligned with calls to improve human-nature relationships as a way to address our climate crisis and ecological separation [93], as well as research that has shown that connectedness with nature is linked to pro-environmental behavior [32]. However, research has also found that some elements of the human-nature relationship are not covered by biophilic design and follow a more dominion-utility framework [94], or values [95]. The research of Lumber, Richardson, and Sheffield [96] found that four of Kellert's [39] values of biophilia were unrelated to nature connectedness. These were fear of nature [97], dominion over nature [98], the utilitarian use of nature [99], and a purely scientific relationship [31]. These types of relationship are often emphasized within capitalistic societies and can be seen as essential pathways for human survival and progress that, unchecked, have led to nature's decline [100-103]. For transformative change, there is clearly an urgent need for a new relationship with nature, yet these negative types of relationship with nature still dominate [103]. Addressing these underlying values and perceptions will be essential to creating effective biophilic design interventions as well as fostering a connection with nature [104].

5.1.4. Connecting Biophilic Design with Environmental Justice, Health, and Climate Change

At a global scale, climate change has been described as: "[ . . ] the most serious threat to global economic, social, and environmental stability in recorded history [ ... ] with many [ ... ] prevalent human diseases linked to climate fluctuations" [105].

Authors [106] have argued that it is our destruction of natural habitats that helped the current Covid-19 pandemic and that we can expect more zoonotic-originated diseases in the future: "There is a single species that is responsible for the Covid-19 pandemic-us. As with the climate and biodiversity crises, recent pandemics are a direct consequence of human activity." [106].

In figuring out how to address future global emergencies, such as climate change and Covid-19, our relationship with nature, and in particular biophilic design, may be key for improving sustainable behavior and, ultimately, our well-being. Rather than relying on abstract universal ideas of nature to encourage sustainable behavior, using design and policy at a building, neighborhood, and city scale to connect our daily lives with nature may encourage connection, improve our health and well-being, and make action feel more meaningful. Then, improving sustainable behavior might help address the current climate and disease crisis. While inaction and business as usual has plagued climate change policies, Covid-19 has exposed the connection between climate change and infectious disease, with those who have been exposed to air pollution dying at a higher rate [5]. This direct and personal connection between climate change and health may prove to be more effective in shifting policy and practice around climate change.

From a health perspective, this may require a shift from risk reduction and the treatment of illnesses to biophilic research and practice that embraces salutogenic thinking, i.e., the medical concept [107] that encourages a focus on factors that improve and support human health and well-being, rather than on factors that reduce illness [108]. With the health and well-being of humans intrinsically linked to the health and well-being of the planetary ecosystems, the combination of biophilic and salutogenic design approaches may provide a more holistic framework to link ecosystem, human, and non-human dimensions. Considering that, at a building scale, research attention has tended to focus on threats to health, a more holistic way of thinking would also be useful to foster health-promoting environments [109]. 
5.1.5. Looking Forward: Engaging with Nature and Fostering a Systems-Thinking Approach

Engaging with nature necessitates a mindset focused on developing the capacity and capability for systems evolution. It is not about a sustainability that maintains what it is-or is attempting to restore something to what it was by only reducing impacts. Rather, it is about creating systems (places, buildings, communities, organizations) that have the capacity to evolve and regenerate toward states of health that thrive over time. The understanding of our position on the planet has a crucial role in building the awareness for regenerative sustainability.

On a larger scale, an emerging trend is the Bio-Leadership, i.e., a concept of an ecosystem made of people and projects transforming leadership by working with nature [110]. Within the design and policy world, the concept switches from a mechanistic perspective (where the world is seen to function as a machine), to a natural fluid approach. This framework has been used to describe the hoped-for next era of our relationship with the environment. This new way of envisioning the nature-human relationship in design and policy aims to nurture a co-evolving mutuality [111] and may provide hope for both a more equitable and regenerative future. If combined with work on equitable access to nature, along with evidence on the benefits of access to nature at multiple scales, this large-scale application of biophilic principles can play a part in restoring both human and ecological health.

\section{Conclusions}

Humans' disconnection with nature has already negatively impacted mental and physical health. Buildings today are often designed, constructed, and operated apart from nature, rather than as a part of nature. Over the last thirty years (since Brundtlandt, 1987) [112], sustainability in design and construction has been a core element in the built environment, and yet climate and biodiversity indicators have worsened, while the impact of building design and practice on health conditions is increasingly researched but still remains opaque. Evidence from the last forty years has shown that contact with nature in general can improve human health, but there are gaps in the application at different scales and a lack of understanding of which research to apply to which situation.

Conversely, biophilic design is growing in popularity, but it still suffers from a lack of specificity on research outcomes and variables. There is a tendency for it is to be dismissed from many design circles as "nice to have but dispensable" versus an effective intervention to improve health and performance. The research on nature and health to date supports many of the biophilic design attributes outlined above; however, in practice, biophilic design is often limited to a few variables, which limits its application in design practice. Furthermore, there is still much that is not known about the potential benefits of biophilic design interventions, individually and as a whole. This gap has not been overcome by the confusion of green design interventions in green buildings and green infrastructure over the last few decades, which may or may not have had any link to evidence-based or biophilic design. It is also complicated by the differing underlying paradigms in nature and health research and design: research that examines nature as a linear input with an expected outcome does not align well with the more philosophical sense of place and lived experience goals of biophilic design. Drawing on some experiences developed in experimental biophilic design, it may help to bridge some of the gaps in traditional nature-health research and address the nuances and complexities of the holistic lived experience, as connected to nature or biophilic design projects. Connecting to sense of place, historicity, and embodied experience in biophilic design may soften some of the criticisms of the adaptive and utilitarian approaches to nature-health research while creating design solutions that work for real people in real contexts.

Lastly, there is still a need to provide a synthesis with respect to the available knowledge about the relationship between nature design and policy interventions, natural systems, and health. This seems to be confirmed by the growing demand from policy makers. 
For instance, in the "Urban green spaces: brief for action", which was published recently, the World Health Organization [113] emphasized the need for a change in urban health initiatives with a strong focus on the creation, promotion, and maintenance of green spaces, with an explicit call for expert advice. How this expertise is developed is a current gap in both education and practice.

The discussion above argues that understanding the strengths and limitations of the most influential research on health and nature can help it support and align with biophilic design at multiple scales. This knowledge can result in a more effective and holistic understanding of how nature can be incorporated into our buildings, neighborhoods, and cities. Critically combining research on health and nature with biophilic design principles may also provide a more holistic and just approach to connecting us with nature and encouraging sustainable behavior. This can further support regenerative policy and action. As we look to life with and after Covid-19, the shape of the future built environment remains unknown, but it provides an opportunity for re-evaluation and new insights about our human, natural, and built environment relationships.

Author Contributions: Conceptualization, M.B.A. and A.L.; methodology, M.B.A. and A.L.; writingoriginal draft preparation, M.B.A. and A.L.; writing—review and editing, M.B.A., A.L., M.B., J.B.; visualization, M.B.A.; supervision, M.B.A., A.L.; funding acquisition, M.B.A., M.B., J.B. All authors have read and agreed to the published version of the manuscript.

Funding: This article is based upon work from COST Action (www.cost.eu) CA16114 'RESTORE’ Rethinking Sustainability Toward a Regenerative Economy, supported by COST (European Cooperation in Science and Technology).

Institutional Review Board Statement: Not applicable.

Informed Consent Statement: Not applicable.

Data Availability Statement: No new data were created or analyzed in this study. Data sharing is not applicable to this article.

Acknowledgments: This article is based upon work from COST Action (www.cost.eu) CA16114 'RESTORE' Rethinking Sustainability Toward a Regenerative Economy, supported by COST (European Cooperation in Science and Technology). COST (European Cooperation in Science and Technology) is a funding agency for research and innovation networks. COST Actions help connect research initiatives across Europe and enable scientists to grow their ideas by sharing them with their peers. This boosts their research, career, and innovation. Authors wish to thank DaeWha Kang Design for authorizing (March 29th, 2021) the use in this article of two images (Figures 1 and 2) of their project "Shard Living Lab", in London.

Conflicts of Interest: The authors declare no conflict of interest.

Declaration: An initial version of this paper was presented at the Greening Cities Shaping Cities Symposium in October 2020. https: / / www.greeningcities-shapingcities.polimi.it/.

\author{
Abbreviations \\ The following abbreviations have been used in this manuscript: \\ ART Attention Restoration Theory \\ PSR Psychophysiological Stress Reduction \\ COST Cooperation in Science and Technology \\ RESTORE Rethinking Sustainability Toward a Regenerative Economy
}

\title{
References
}

1. Hadavi, S.; Kaplan, R.; Hunter, M.C.R. Environmental affordances: A practical approach for design of nearby outdoor settings in urban residential areas. Landsc. Urban Plan. 2015, 134, 19-32. [CrossRef]

2. Kaplan, S. The restorative benefits of nature: Toward an integrative framework. J. Environ. Psychol. 1995, 15, 169-182. [CrossRef]

3. Thompson, C.W.; Roe, J.; Aspinall, P.; Mitchell, R.; Clow, A.; Miller, D. More green space is linked to less stress in deprived communities: Evidence from salivary cortisol patterns. Landsc. Urban Plan. 2012, 105, 221-229. [CrossRef]

4. Acuto, M. COVID-19: Lessons for an Urban(izing) World. One Earth 2020, 2, 317-319. [CrossRef] 
5. Wu, X.; Nethery, R.C.; Sabath, B.M.; Braun, D.; Dominici, F. Exposure to air pollution and COVID-19 mortality in the United States. Available online: https:/ / projects.iq.harvard.edu/covid-pm?gsBNFDNDN=undefined\&utm_campaign=wp_the_energy_ 202\&utm_medium $=$ email\&utm_source=newsletter\&wpisrc=nl_energy202 (accessed on 12 May 2020).

6. $\quad$ Beute, F.; Andreucci, M.B.; Lammel, A.; Davies, Z.; Glanville, J.; Keune, H.; Marselle, M.; O’Brien, L.A.; Olszewska-Guizzo, A.; Remmen, R.; et al. Types and Characteristics of Urban and Peri-Urban Green Spaces Having an Impact on Human Mental Health and Wellbeing. Report Prepared by an EKLIPSE Expert Working Group; Centre for Ecology \& Hydrology: Wallingford, UK, 2020.

7. Beute, F.; Davies, Z.; de Vries, S.; Glanville, J.; Keune, H.; Lammel, A.; Marselle, M.; O’Brien, L.; Olszewska-Guizzo, A.; Remmen, R.; et al. Types and Characteristics of Urban and Peri-Urban Blue Spaces Having an Impact on Human Mental Health and Wellbeing. Report Prepared by an EKLIPSE Expert Working Group; Centre for Ecology \& Hydrology: Wallingford, UK, 2020.

8. Surico, J. The Power of Parks in a Pandemic. Available online: https://www.bloomberg.com/news/articles/2020-04-09/in-apandemic-the-parks-are-keeping-us-alive (accessed on 23 June 2020).

9. Beatley, T. Handbook of Biophilic City Planning and Design; Island Press: Washington, DC, USA, 2016.

10. Frumkin, H.; Bratman, G.N.; Breslow, S.J.; Cochran, B.; Kahn Jr, P.H.; Lawler, J.J.; Wolf, K.L. Nature contact and human health: A research agenda. Environ. Health Perspect. 2017, 125, 075001. [CrossRef] [PubMed]

11. Loder, A. Small-Scale Urban Greening: Creating Places of Health, Creativity, and Ecological Sustainability; Routledge: Abingdon, UK, 2020.

12. Yin, R.K. Application of Case Study Research; Sage: London, UK; New Delhi, India, 1993.

13. Yin, R.K. Case Study Research: Design and Methods; Sage: London, UK; New Delhi, India, 1994.

14. Keniger, L.E.; Gaston, K.J.; Irvine, K.N.; Fuller, R.A. What are the Benefits of Interacting with Nature? Int. J. Environ. Res. Public Heal. 2013, 10, 913-935. [CrossRef] [PubMed]

15. Hartig, T.; Mitchell, R.; De Vries, S.; Frumkin, H. Nature and Health. Annu. Rev. Public Heal. 2014, 35, 207-228. [CrossRef]

16. Dzhambov, A.M.; Markevych, I.; Hartig, T.; Tilov, B.; Arabadzhiev, Z.; Stoyanov, D.; Gatseva, P.; Dimitrova, D.D. Multiple pathways link urban green- and bluespace to mental health in young adults. Environ. Res. 2018, 166, 223-233. [CrossRef]

17. Bratman, G.N.; Anderson, C.B.; Berman, M.G.; Cochran, B.; De Vries, S.; Flanders, J.; Folke, C.; Frumkin, H.; Gross, J.J.; Hartig, T.; et al. Nature and mental health: An ecosystem service perspective. Sci. Adv. 2019, 5, eaax0903. [CrossRef]

18. Labib, S.; Lindley, S.; Huck, J.J. Spatial dimensions of the influence of urban green-blue spaces on human health: A systematic review. Environ. Res. 2020, 180, 108869. [CrossRef]

19. Ballard, B. Biophilic office designs drive productivity and creativity. European CEO. Available online: https://www.europeanceo. com/business-and-management/biophilic-office-designs-drive-productivity-and-creativity/ (accessed on 16 June 2019 ).

20. Millennium Ecosystem Assessment. Ecosystems and Human Well-being: Synthesis; Island Press: Washington, DC, USA, 2005.

21. Gómez-Baggethun, E.; Barton, D.N. Classifying and valuing ecosystem services for urban planning. Ecol. Econ. 2013, 86, 235-245. [CrossRef]

22. Wilson, E.O. Biophilia: The Human Bond with Other Species; Harvard University Press: Cambridge, MA, USA, 1984.

23. Somarakis, G.; Stagakis, S.; Chrysoulakis, N. (Eds.) ThinkNature Nature-Based Solutions Handbook. ThinkNature project funded by the EU Horizon 2020 research and innovation programme under grant agreement No. 730338. 2019. Available online: https:/ / platform.think-nature.eu/system/files/thinknature_handbook_final_print_0.pdf (accessed on 15 March 2021). [CrossRef]

24. Kaplan, R.; Kaplan, S. Preference, Restoration, and Meaningful Action in the Context of Nearby Nature. In Urban Place: Reconnecting with the Natural World; Barlett, P., Ed.; MIT Press: Cambridge, UK, 2005; p. 330.

25. Ulrich, R.S. Biophilia, Biophobia, and Natural Landscapes. In The Biophilia Hypothesis; Kellert, S.E.O.W., Ed.; Island Press: Washington, DC, USA, 1993; pp. 74-137.

26. Kaplan, R.; Kaplan, S. The Experience of Nature: A Psychological Perspective; Cambridge University Press: Cambridge, UK, 1989.

27. Hartig, T.; Mang, M.; Evans, G.W. Restorative Effects of Natural Environment Experiences. Environ. Behav. 1991, $23,3-26$. [CrossRef]

28. Korpela, K.M.; Ylén, M.; Tyrväinen, L.; Silvennoinen, H. Determinants of restorative experiences in everyday favorite places. Heal. Place 2008, 14, 636-652. [CrossRef]

29. Fromm, E. The Anatomy of Human Destructiveness; Holt, Rinehart and Winston: New York, NY, USA, 1973.

30. Church, S.P. Exploring Green Streets and rain gardens as instances of small scale nature and environmental learning tools. Landsc. Urban Plan. 2015, 134, 229-240. [CrossRef]

31. Davison, A. The trouble with nature: Ambivalence in the lives of urban Australian environmentalists. Geoforum 2008, 39, 1284-1295. [CrossRef]

32. Liuna, G.; Jingke, X.; Lijuan, Y.; Wenjun, Z.; Kexin, Z. Connections with Nature and Environmental Behaviors. PLoS ONE 2015, 10. [CrossRef]

33. Perrin, J.L.; Benassi, V.A. The connectedness to nature scale: A measure of emotional connection to nature? J. Environ. Psychol. 2009, 29, 434-440. [CrossRef]

34. Wang, J.; Geng, L.; Schultz, P.W.; Zhou, K. Mindfulness Increases the Belief in Climate Change: The Mediating Role of Connectedness With Nature. Environ. Behav. 2019, 51, 3-23. [CrossRef] 
35. Wyles, K.J.; White, M.P.; Hattam, C.; Pahl, S.; King, H.; Austen, M. Are Some Natural Environments More Psycho-logically Beneficial Than Others? The Importance of Type and Quality on Connectedness to Nature and Psychological Restoration. Environ. Behav. 2019, 51, 111-143. [CrossRef]

36. Braubach, M.; Egorov, A.; Mudu, P.; Wolf, T.; Thompson, C.W.; Martuzzi, M. Effects of Urban Green Space on Environmental Health, Equity and Resilience. In Nature-Based Solutions to Climate Change Adaptation in Urban Areas: Linkages between Science, Policy and Practice; Springer International Publishing: Cham, Switzerland; Berlin/Heidelberg, Germany, 2017 ; pp. 187-205.

37. Kim, D.; Jin, J. Does happiness data say urban parks are worth it? Landsc. Urban Plan. 2018, 178, 1-11. [CrossRef]

38. Han, B.; Cohen, D.A.; Derose, K.P.; Marsh, T.; Williamson, S.; Raaen, L. How much neighborhood parks contribute to local residents' physical activity in the City of Los Angeles: A meta-analysis. Prev. Med. 2014, 69, S106-S110. [CrossRef]

39. Kellert, S.R.; Wilson, E.O. The Biophilia Hypothesis; Island Press: Washington, DC, USA, 1993.

40. Barton, J.; Griffin, M.; Pretty, J. Exercise, nature and socially interactive-based initiatives improve mood and self-esteem in the clinical population. Perspect. Public Heal. 2011, 132, 89-96. [CrossRef]

41. Berg, M.M.V.D.; Van Poppel, M.; Van Kamp, I.; Ruijsbroek, A.; Triguero-Mas, M.; Gidlow, C.; Nieuwenhuijsen, M.J.; Gražulevičiene, R.; Van Mechelen, W.; Kruize, H.; et al. Do Physical Activity, Social Cohesion, and Loneliness Mediate the Association Between Time Spent Visiting Green Space and Mental Health? Environ. Behav. 2019, 51, 144-166. [CrossRef]

42. Schipperijn, J.; Bentsen, P.; Troelsen, J.; Toftager, M.; Stigsdotter, U.K. Associations between physical activity and characteristics of urban green space. Urban For. Urban Green. 2013, 12, 109-116. [CrossRef]

43. PennPraxis. Green2015: An Action Plan for the First 500 Acres. Philadelphia: City of Philadelphia. Available online: http: / / planphilly.com/green2015 (accessed on 30 August 2020).

44. City of Philadelphia. Greenworks: A vision for a sustainable Philadelphia; Office of Sustainability: Philadelphia, PA, USA, 2016.

45. Peters, K.; Elands, B.; Buijs, A. Social interactions in urban parks: Stimulating social cohesion? Urban For. Urban Green. 2010, 9 , 93-100. [CrossRef]

46. Holt-Lunstad, J.; Smith, T.B.; Layton, J.B. Social Relationships and Mortality Risk: A Meta-analytic Review. PLoS Med. 2010, 7, e1000316. [CrossRef]

47. Sun, Z.; Zhu, D. Exposure to outdoor air pollution and its human health outcomes: A scoping review. PLoS ONE 2019, 14, e0216550. [CrossRef]

48. Klompmaker, J.O.; Hoek, G.; Bloemsma, L.D.; Wijga, A.H.; van den Brink, C.; Brunekreef, B.; Janssen, N.A. As-sociations of combined exposures to surrounding green, air pollution and traffic noise on mental health. Environ. Int. 2019, 129, 525-537. [CrossRef]

49. Calderón-Garcidueñas, L.; Torres-Jardón, R.; Kulesza, R.J.; Park, S.B.; D'Angiulli, A. Air pollution and detrimental effects on children's brain. The need for a multidisciplinary approach to the issue complexity and challenges. Front. Hum. Neurosci. 2014, 8,613 .

50. von Lindern, E.; Hartig, T.; Lercher, P. Traffic-related exposures, constrained restoration, and health in the residential context. Health Place 2016, 39, 92-100. [CrossRef]

51. Tuan, Y.F. Rootedness versus sense of place. Landscape 1980, 24, 3-8.

52. Williams, D.R. Making sense of 'place': Reflections on pluralism and positionality in place research. Landsc. Urban Plan. 2014, 131, 74-82. [CrossRef]

53. Zufferey, C.; King, S. Social work learning spaces: The Social Work Studio. High. Educ. Res. Dev. 2016, 35, 395-408. [CrossRef]

54. Cornell Health. Nature Rx. Cornell University. Available online: https:// health.cornell.edu/resources/health-topics/nature-rx (accessed on 16 June 2019).

55. Kallen, C. NaturePHL Bringing 'Nature Prescriptions' to Local Doctors' Offices. Family Focus Media, Philadelphia. Available online: http:/ / familyfocus.org/nature-phl-nature-prescriptions-philadelphia (accessed on 16 June 2019).

56. Lachowycz, K.; Jones, A.P. Towards a better understanding of the relationship between greenspace and health: Development of a theoretical framework. Landsc. Urban Plan. 2013, 118, 62-69. [CrossRef]

57. Trentelman, C.K. Place Attachment and Community Attachment: A Primer Grounded in the Lived Experience of a Community Sociologist. Soc. Nat. Resour. 2009, 22, 191-210. [CrossRef]

58. Stedman, R.C.; Beckley, T.M. If we knew what it was we were doing, it would not be called research, would it? Soc. Nat. Resour. 2007, 20, 939-943. [CrossRef]

59. Williams, D.R.; Patterson, M.E. Snapshots of What, Exactly? A Comment on Methodological Experimentation and Conceptual Foundations in Place Research. Soc. Nat. Resour. 2007, 20, 931-937. [CrossRef]

60. Kellert, S.R. Dimensions, Elements, and Attributes of Biophilic Design. In Biophilic Design: The Theory, Science, and Practice of Bringing Buildings to Life; Kellert, S.R., Heerwagen, J., Mador, M., Eds.; John Wiley \& Sons: Hoboken, NJ, USA, 2018.

61. Browning, W.D.; Ryan, C.O.; Clancy, J.O. 14 Patterns of Biophilic Design; Terrapin Bright Green LLC: New York, NY, USA, 2014.

62. McGee, B.; Park, N.; Portillo, M.; Bosch, S.; Swisher, M. Diy Biophilia: Development of the Biophilic Interior Design Matrix as a Design Tool. J. Inter. Des. 2019, 44, 201-221. [CrossRef]

63. Pallasmaa, J.; Amundsen, M. Q\&A with Juhani Pallasmaa on Architecture, Aesthetics of Atmospheres and the Passage of Time Questions-réponses avec Juhani Pallasmaa sur l'architecture, l'esthétique des ambiances et les effets du temps. Ambiances. Environnement sensible, architecture et espace urbain Comptes-rendus. Available online: http://journals.openedition.org/ ambiances/1257 (accessed on 30 August 2019). 
64. Reeve, A.; Desha, C.; Hargroves, K.; Newman, P. Informing healthy building design with biophilic urbanism design principles: A review and synthesis of current knowledge and research. In Proceedings of the 10th International Conference on Healthy Buildings, Brisbane, Australia., 8-12 July 2012.

65. Statista. Forecasted population in London (UK) from 2019 to 2041. Available online: https://www.statista.com/statistics/379035 /london-population-forecast/ (accessed on 16 March 2021).

66. Greenspace Information for Greater London CIC (GiGL). Key London Figures. Available online: https://www.gigl.org.uk/ keyfigures / (accessed on 16 March 2021).

67. DaeWha Kang Design and Aldworth James \& Bond. Using cutting-edge fabrication technology to construct unique working spaces in the UK's tallest building. Kellert, S.R., and Calabrese, E.F. 2015. The practice of Biophilic design. Available online: www.biophilic-design.com (accessed on 10 February 2021).

68. Kellert, S.R.; Calabrese, E.F. The practice of Biophilic design. Available online: www.biophilic-design.com (accessed on 10 February 2021).

69. Dunnett, N. Naturalistic Planting Design: The Essential Guide; Filbert Press: London, UK, 2019.

70. Smith, C.J.; Relph, E. Place and Placelessness. Geogr. Rev. 1978, 68, 116. [CrossRef]

71. Loder, A. 'There's a meadow outside my workplace': A phenomenological exploration of aesthetics and green roofs in Chicago and Toronto. Landsc. Urban Plan. 2014, 126, 94-106. [CrossRef]

72. Klinenberg, E. Heat Wave: A Social Autopsy of Disaster in Chicago; University of Chicago Press: Chicago, IL, USA, 2002.

73. City of Chicago, Department of Transportation. The Chicago Green Alley Handbook: An Action Guide to Create a Greener, Environmentally Sustainable Chicago. Available online: https://www.chicago.gov/dam/city/depts/cdot/GreenAlleyHandbook.pdf (accessed on 12 June 2019).

74. Berkshire, M. Chicago Green Projects. In Small-Scale Urban Greening: Creating Places of Health, Creativity, And Ecological Sustainability; Loder, A., Ed.; Routledge: Abingdon, UK, 2020; p. 94.

75. City of Chicago, Department of Water Management. Green Stormwater Infrastructure Strategy. Available online: https://www. chicago.gov/content/dam/city/progs/env/ChicagoGreenStormwaterInfrastructureStrategy.pdf (accessed on 10 July 2015).

76. City of Chicago, Department of the Environment. New Stormwater Management Ordinance. Available online: https://www. chicago.gov/content/dam/city/depts/water/general/Engineering/MS4/MS4_Stormwater_Plan.pdf (accessed on 4 September 2018).

77. Andreucci, M.B. Progettare L'involucro Urbano. Casi Studio di Progettazione Tecnologica Ambientale; Wolters Kluwer: Milano, Italy, 2019.

78. 100 Resilient Cities. Available online: https://100resilientcities.org/ (accessed on 10 May 2019).

79. Gobster, P.H.; Stewart, W.P.; van Riper, C.J.; Williams, A.R. Vacant Lot Stewardship and the Creation of New Natures in Chicago. In Proceedings of the International Association for Landscape Ecology Conference, Chicago, IL, USA, 8-12 April 2018.

80. WLS-TV Chicago. City of Chicago selling more than $4 \mathrm{~K}$ vacant lots for 1.ABC7EyewitnessNews. Available online: https:// abc7chicago.com/news/city\$-\$of\$-\$chicago\$-\$selling\$-\$more\$-\$than\$-\$4k-\$vacant\$-\$lots-\$for\$-\$1.ABC7EyewitnessNews. November292019.https:/ /abc7chicago.com/news/city\$-\$of\$-\$chicago\$-\$selling\$-\$more\$-\$than\$-\$4k-\$vacant\$-\$lots\$-\$for\$\$1- /1630671/ (accessed on 29 November 2019).

81. Lindsey, G.; Qi, Y.; Gobster, P.H.; Sachdeva, S. The 606 at Three: Trends in Use of Chicago's Elevated Rail- Trail, Proceedings of the Fábos Conference on Landscape and Greenway Planning, 6, 37. Available online: https://scholarworks.umass.edu/fabos/ vol6/iss1/37 (accessed on 10 June 2020).

82. The Trust for Public Land. Our Story. The 606. Available online: https://www.the606.org/about/story/ (accessed on 26 May 2019).

83. Smith, G.; Duda, S.; Lee, J.M.; Thompson, M. Measuring the Impact of the 606: Understanding How a Large Public In-vestment Impacted the Surrounding Housing Market. Chicago: Institute for Housing Studies at DePaul University. Available online: https:/ / www.housingstudies.org/media/filer_public/2016/10/31/ihs_measuring_the_impact_of_the_606.pdf (accessed on 12 June 2019).

84. Rodkin, D. Was gentrification around the 606 inevitable? Crain's Chicago Business. Available online: https://www. chicagobusiness.com/residential-real-estate/was-gentrification-around-606-inevitable (accessed on 13 December 2019).

85. Wessel, M. Chicago's Resiliency Plan Aims for Equity. Next City. Available online: https://nextcity.org/daily/entry/chicagosresiliency-plan-aims-for-equity (accessed on 24 April 2019).

86. Green Stormwater Infrastructure Partners. Sustainable Business Network of Greater Philadelphia. The Economic Impact of Green City, Clean Waters: The First Five Years. 2016. Available online: https://gsipartners.sbnphiladelphia.org/wp-content/uploads/ 2014/07/Local-Economic-Impact-Report_First-Five-Years-GCCW_full-downloadable-web2.pdf (accessed on 12 June 2019).

87. Berkshire, M. Resilient Corridors. In Rockefeller Foundation 100 Resilient Cities, Chicago: A plan for Inclusive Growth and a Connected City, City of Chicago. Available online: https://resilient.chicago.gov/download/Resilient\%20Chicago.pdf (accessed on 5 June 2019).

88. American Society of Landscape Architects. Chicago Resilient Corridors. Available online: https://il-asla.org/award/chicagoresilient-corridors / (accessed on 2 October 2020). 
89. Macfarlane, R. London Becomes the World's First National Park City. London National Park City. Available online: https: / / www.nationalparkcity.london/press/24-media/130-london-becomes-the-world-s-first-national-park-city (accessed on 14 June 2019).

90. Choudhry, K.Z.; Coles, R.; Qureshi, S.; Ashford, R.; Khan, S.; Mir, R.R. A review of methodologies used in studies investigating human behaviour as determinant of outcome for exposure to 'naturalistic and urban environments'. Urban For. Urban Green. 2015, 14, 527-537. [CrossRef]

91. Li, D.; Deal, B.; Zhou, X.; Slavenas, M.; Sullivan, W.C. Moving beyond the neighborhood: Daily exposure to nature and adolescents' mood. Landsc. Urban Plan. 2018, 173, 33-43. [CrossRef]

92. Taylor, R.P. Reduction of Physiological Stress Using Fractal Art and Architecture. Leon 2006, 39, 245-251. [CrossRef]

93. Richardson, M.; Dobson, J.; Abson, D.J.; Lumber, R.; Hunt, A.; Young, R.; Moorhouse, B. Applying the pathways to nature connectedness at a societal scale: A leverage points perspective. Ecosyst. People 2020, 16, 387-401. [CrossRef]

94. Schultz, W.P.; Zelezny, L.C. Values as predictors of environmental attitudes: Evidence for consistency across cultures. J. Environ. Psychol. 1999, 19, 255-265. [CrossRef]

95. Stern, P.C.; Dietz, T.; Kalof, L.; Guagnano, G.A. The new environmental paradigm in social psychological perspective. Environ. Behav. 1995, 27, 723-745. [CrossRef]

96. Lumber, R.; Richardson, M.; Sheffield, D. Beyond knowing nature: Contact, emotion, compassion, meaning, and beauty are pathways to nature connection. PLoS ONE 2017, 12, e0177186. [CrossRef]

97. Nash, R. Wilderness and the American Mind. Yale University Press: New Haven, CT, USA, 2001.

98. Merchant, C. Reinventing Nature: Western Culture as a Recovery Narrative. In Uncommon Ground; Cronon, W., Ed.; W. W. Norton \& Company: New York, NY, USA, 1995; pp. 132-159.

99. Smith, N. The Production of Nature. In Future Natural: Nature, Science, Culture; Robertson, G.M.M., Tichner, L., Curtis, B., Putnam, T., Eds.; Routledge: London, UK, 1996; pp. 35-54.

100. Baskin, J. Paradigm dressed as epoch: The ideology of the antropocene. Environ. Values 2015, 24, 9. [CrossRef]

101. Catton, W.R.; Dunlap, R.E. Environmental Sociology: A New paradigm. Am. Sociol. 1978, 13, 41-49.

102. IPBES. Summary for Policymakers of the Global Assessment Report on Biodiversity and Ecosystem Services of the Intergovernmental Science-Policy Platform on Biodiversity and Ecosystem Services; Díaz, S., Settele, J., Brondízio, E.S., Ngo, H.T., Guèze, M., Agard, J., Arneth, A., Balvanera, P., Brauman, K.A., Butchart, S.H.M., et al., Eds.; IPBES: Bonn, Germany, 2019.

103. Ison, R.; Straw, E. The Hidden Power of Systems Thinking: Governance in a Climate Emergency; Routledge: London, UK, 2020.

104. Loder, A. Regeneration. Between Ecological and Human Systems. In Progettare l'involucro Urbano: Casi Studio di Progettazione Tecnologica Ambientale; Andreucci, M.B., Ed.; Wolters Kluwer: Milano, Italy, 2019; p. 179.

105. Africa, J.; Heerwagen, J.; Loftness, V.; Ryan Balagtas, C. Biophilic Design and Climate Change: Performance Parameters for Health. Front. Built Environ. 2019, 5, 28. [CrossRef]

106. Settele, J.; Díaz, S.; Brondizio, D.; Daszak, P. COVID-19 Stimulus Measures Must Save Lives, Protect Livelihoods, and Safeguard Nature to Reduce the Risk of Future Pandemics. Intergovernmental Science-Policy Platform on Biodiversity and Ecosystem Services (IPBES Report). Available online: https:/ / ipbes.net/covid19stimulus (accessed on 10 June 2020).

107. Antonovsky, A. Unravelling the Mystery of Health; Jossey-Bass Inc: San Francisco, CA, USA, 1987.

108. Brown, M. FutuREstorative: Working Towards a New Sustainability; RIBA Publishing: London, UK, 2016.

109. Loder, A.; Gray, W.A.; Timm, S. The international WELL Building Institute's Global Research Agenda. Available online: https:/ / marketing.wellcertified.com/global-research-agenda (accessed on 10 February 2021).

110. Roberts, A. How would nature Change Leadership? Available online: https://www.ted.com/talks/andres_roberts_how_would_ nature_change_leadership (accessed on 7 May 2020).

111. Mang, P.; Haggard, B. Regenerative Development and Design: A framework for Evolving Sustainability; Wiley: Hoboken, NJ, USA, 2016.

112. World Commission on Environment and Development. Our Common Future; Oxford University Press: Oxford, UK, 1987.

113. WHO Regional Office for Europe. Urban Green Space Interventions and Health: A Review of Impacts and Effectiveness. Copenhagen: WHO Regional Office for Europe. Available online: http:/ / www.euro.who.int/_data/assets/ (accessed on 12 March 2018). 